\title{
Cardiometabolic Risk Factors in Patients With Ankylosing Spondylitis
}

\author{
Mehmet UÇAR, ${ }^{1}$ Savaş SARIKAYA, ${ }^{2}$ Ümit SARP, ${ }^{3}$ Yaşar TURAN, ${ }^{2}$ Lütfi AKYOL, ${ }^{4}$ \\ Elif BÖREKÇİ, ${ }^{4}$ Ali Riza ERBAY, ${ }^{2}$ Vahit DEMİR ${ }^{5}$ \\ ${ }^{1}$ Department of Physical Medicine and Rehabilitation, Medical Faculty of Bozok University, Yozgat, Turkey \\ ${ }^{2}$ Department of Cardiology, Medical Faculty of Bozok University, Yozgat, Turkey \\ ${ }^{3}$ Department of Physical Medicine and Rehabilitation, Yozgat State Hospital, Yozgat, Turkey \\ ${ }^{4}$ Department of Internal Medicine, Medical Faculty of Bozok University, Yozgat, Turkey \\ ${ }^{5}$ Department of Cardiology, Yozgat State Hospital, Yozgat, Turkey
}

\begin{abstract}
Objectives: This study aims to evaluate cardiometabolic risk factors in ankylosing spondylitis (AS) patients and their relationship with epicardial fat thickness (EFT).

Patients and methods: The study included 50 consecutive AS patients ( 29 males, 21 females; mean age $40.5 \pm 9.4$ years; range 25 to 60 years) with a median disease duration of 8.3 years and 50 healthy controls ( 33 males, 17 females; mean age $39.8 \pm 6.4$ years, range 24 to 58 years). All patients' EFT was measured with echocardiography.

Results: Both body mass index and waist circumference measurements were higher in AS patients than healthy controls (25.4 \pm 3.5 . vs. $24.5 \pm 2.9 \mathrm{~kg} / \mathrm{m}^{2}, \mathrm{p}=0.005 ; 96.2 \pm 10.8$ vs. $86.7 \pm 12.6 \mathrm{~cm}, \mathrm{p}<0.001$; respectively). Triglyceride levels were higher in AS patients than healthy controls $(123.0 \pm 47.7$ vs. $110.1 \pm 61.0 \mathrm{mg} / \mathrm{dL}, \mathrm{p}=0.009$; respectively). High-density lipoprotein cholesterol levels were lower in AS patients than healthy controls ( $41.3 \pm 7.0$ vs. $51.9 \pm 7.0 \mathrm{mg} / \mathrm{dL}, \mathrm{p}<0.001$; respectively). The EFT of AS patients was greater $(0.53 \pm 0.14 \mathrm{vs} .0 .45 \pm 0.02 \mathrm{~cm}, \mathrm{p}<0.001$; respectively) and was positively correlated with age $(r=0.420, p=0.002)$, disease duration $(r=0.609, p<0.001)$, body mass index $(r=0.419, p=0.002)$, waist circumference $(r=0.469, p<0.001)$, and triglyceride $(r=0.434, p=0.002)$ levels; and negatively correlated with high-density lipoprotein cholesterol levels $(r=-0.662, p<0.001)$.
\end{abstract}

Conclusion: As a cardiometabolic risk factor, EFT was greater in AS patients. EFT is a noninvasive method to evaluate cardiometabolic risk factors in AS patients.

Keywords: Ankylosing spondylitis; cardiometabolic risk factors; epicardial fat thickness.

Ankylosing spondylitis (AS) is an inflammatory disease associated with metabolic syndrome and atherosclerosis. ${ }^{1}$ In AS patients, risk factors for cardiovascular disease including valve problems, rhythm disturbances, hypertension, and atherosclerosis are increased. ${ }^{2,3}$ Such patients suffer increased cardiovascular mortality attributable to atherosclerosis. ${ }^{4}$ In addition, metabolic syndrome risk factors including obesity, hypertension, hyperlipidemia, disturbances of glucose metabolism, and enhanced insulin resistance are elevated in AS patients. ${ }^{5}$
Epicardial fat tissue (EFT) surrounds the heart and metabolically active organs. Recently, several studies have shown that excess EFT was associated with insulin resistance, ${ }^{6}$ increased cardiometabolic risk,$^{7}$ elevated inflammatory marker levels, ${ }^{8,9}$ and coronary artery disease..$^{10,11}$

Nilgün et al. ${ }^{12}$ evaluated 26 AS patients and 26 healthy controls, and they showed that although EFT was elevated in AS patients, this was not associated with either the levels of subclinical atherosclerosis markers or disease duration. 
Resorlu et al. ${ }^{13}$ studied 40 AS patients and 40 healthy controls, and they found that EFT was higher in AS patients and it was associated both with carotid intima media thickness and disease duration. Thus, this study aimed to evaluate cardiometabolic risk factors in AS patients and their relationship with EFT.

\section{PATIENTS AND METHODS}

Our study population included 50 consecutive patients with AS (29 males, 21 females; mean age of $40.5 \pm 9.4$ years; range 25 to 60 years) with a median disease duration of 8.3 years, and 50 healthy controls (33 males, 17 females; mean age $39.8 \pm 6.4$ years; range 24 to 58 years). All patients fulfilled the modified New York criteria for AS. ${ }^{12}$ Detailed histories were taken and patients were comprehensively analyzed. Exclusion criteria were congestive heart failure, presence of valvular heart disease, pacemaker implantation, atrial fibrillation/flutter, frequent ventricular pre-excitation and/or abnormalities in atrioventricular conduction, renal failure, myocardial infarction, cerebrovascular accident, and/or poor echocardiographic imaging resolution.

The study was conducted in accordance with the tenets of the Declaration of Helsinki and approved by our local ethics committee. Informed consents were obtained from all patients.

All patients underwent echocardiography. After resting for 15 minutes, all patients underwent two-dimensional and Doppler echocardiographic evaluations employing a $3.5 \mathrm{MHz}$ transducer (Presoundalpha 7, IPF 1701 Model, 2009; Hitachi Aloka Medical, Ltd. Tokyo, Japan). Standard parasternal and apical echocardiograms were recorded with patients lying in the left lateral position. EFT was measured perpendicularly on the free wall of the right ventricle at end systole, over three cardiac cycles. The parasternal longand short-axis views afforded the most accurate measurements of epicardial adipose tissue depth in the right ventricle; the cursor beam orientation was optimized for each patient. Maximum EFT was recorded at a point on the free wall of the right ventricle, along the midline of an ultrasonic beam delivered perpendicular to the aortic annulus, which served as an anatomical landmark.
Blood samples were drawn by venipuncture, after patients had fasted for at least eight hours, to measure routine parameters. Fasting blood glucose, serum creatinine, total cholesterol, highdensity lipoprotein cholesterol (HDL), low-density lipoprotein cholesterol, and triglyceride (TG) levels were recorded using standard methods.

\section{Statistical analysis}

Statistical analyses were performed using SPSS for Windows version 15.0 software program (SPSS Inc., Chicago, IL, USA). The Student's t-test or Mann-Whitney U-test was employed to compare differences between continuous variables. The Chi-squared test was used to compare the distributions of categorical data. Pearson correlation coefficients were used between EFT values and clinical parameters. $\mathrm{P}<0.05$ was considered as statistically significant.

\section{RESULTS}

In terms of basic clinical and demographic characteristics, both groups were similar in age, body mass index (BMI), waist circumference (WC), presence of hypertension and/or diabetes mellitus and levels of TG, HDL, total cholesterol, low-density lipoprotein cholesterol, and fasting glucose level (Table 1). Both the BMI and WC were higher in AS patients than healthy controls $\left(25.4 \pm 3.5\right.$ vs. $24.5 \pm 2.9 \mathrm{~kg} / \mathrm{m}^{2}, \quad \mathrm{p}=0.005$; $96.2 \pm 10.8$ vs. $86.7 \pm 12.6 \mathrm{~cm}, \quad \mathrm{p}<0.001$; respectively). AS patients also had higher TG levels $(123.0 \pm 47.7$ vs. $110.1 \pm 61.0 \mathrm{mg} / \mathrm{dL}, \mathrm{p}=0.009$; respectively), lower HDL levels $(41.3 \pm 7.0$ vs. $51.9 \pm 7.0 \mathrm{mg} / \mathrm{dL}, \mathrm{p}<0.001$; respectively) and greater EFT values $(0.53 \pm 0.14$ vs. $0.45 \pm 0.02 \mathrm{~cm}$, $\mathrm{p}<0.001$; respectively). In AS patients, EFT was correlated with age $(r=0.420, p=0.002)$, disease duration $(\mathrm{r}=0.609, \mathrm{p}<0.001)$, BMI $(\mathrm{r}=0.419$, $\mathrm{p}=0.002)$, WC $(\mathrm{r}=0.469, \mathrm{p}<0.001)$ and TG $(\mathrm{r}=0.434, \mathrm{p}=0.002)$, and HDL levels $(\mathrm{r}=-0.662$, $\mathrm{p}<0.001)$. The correlations between EFT and disease duration, WC, and HDL level in AS patients are shown in Figure 1.

\section{DISCUSSION}

When compared with controls, AS patients had greater EFT, higher values for cardiometabolic 
Table 1. Demographic and clinical characteristics of subjects

\begin{tabular}{|c|c|c|c|c|c|c|c|c|c|c|c|}
\hline & \multicolumn{5}{|c|}{ Ankylosing spondylitis patients $(\mathrm{n}=50)$} & \multicolumn{5}{|c|}{ Controls $(n=50)$} & \multirow[b]{2}{*}{$p$} \\
\hline & $\mathrm{n}$ & $\%$ & Mean \pm SD & Median & Min.-Max. & $\mathrm{n}$ & $\%$ & Mean \pm SD & Median & Min.-Max. & \\
\hline Age (years) & & & $40.5 \pm 9.4$ & & & & & $39.8 \pm 6.4$ & & & 0.846 \\
\hline \multicolumn{12}{|l|}{ Sex } \\
\hline Female & 21 & 42 & & & & 17 & 34 & & & & 0.410 \\
\hline Body mass index $\left(\mathrm{kg} / \mathrm{cm}^{2}\right)$ & & & $25.4 \pm 3.5$ & & & & & $24.9 \pm 2.5$ & & & 0.005 \\
\hline Waist circumference $(\mathrm{cm})$ & & & $96.2 \pm 10.8$ & & & & & $86.7 \pm 12.6$ & & & $<0.001$ \\
\hline Disease duration (years) & & & & 8.3 & $5-23$ & & & & - & - & \\
\hline Diabetes mellitus & 2 & 4 & & & & - & - & & & & 0.153 \\
\hline Hypertension & 4 & 8 & & & & - & - & & & & 0.126 \\
\hline Epicardial fat thickness (mm) & & & $0.53 \pm 0.14$ & & & & & $0.45 \pm 0.02$ & & & $<0.001$ \\
\hline C-reactive protein (mg/dL) & & & $13.4 \pm 11.5$ & & & & & $1.6 \pm 3.4$ & & & $<0.001$ \\
\hline Glucose $(\mathrm{mg} / \mathrm{dL})$ & & & $96.7 \pm 11.8$ & & & & & $97.1 \pm 8.3$ & & & 0.714 \\
\hline Triglyceride (mg/dL) & & & $123.0 \pm 47.7$ & & & & & $110.1 \pm 61.0$ & & & 0.009 \\
\hline $\operatorname{HDL}(\mathrm{mg} / \mathrm{dL})$ & & & $41.3 \pm 7.0$ & & & & & $51.9 \pm 7.0$ & & & $<0.001$ \\
\hline Total cholesterol (mg/dL) & & & $172.4 \pm 53.7$ & & & & & $180.3 \pm 47.4$ & & & 0.255 \\
\hline $\mathrm{LDL}(\mathrm{mg} / \mathrm{dL})$ & & & $122.2 \pm 33.4$ & & & & & $126.6 \pm 34.3$ & & & 0.275 \\
\hline
\end{tabular}

risk factors including BMI, WC, and TG levels and lower values for HDL. EFT values were correlated positively with BMI, WC, and disease duration, and negatively with HDL level. Thus, cardiometabolic risk factors were elevated in AS patients.

Ankylosing spondylitis is a chronic inflammatory disease involving both the axial skeleton and extra-articular organs including the eyes, lungs, neurological system, and heart. ${ }^{15-18}$ Inflammatory rheumatic diseases trigger cardiovascular conditions, increasing mortality and morbidity. ${ }^{19}$ The risk of atherosclerosis, in which inflammation plays a primary role, was increased in AS patients.

Assessment of EFT by echocardiography was validated by Iacobellis et al. ${ }^{20,21}$ Such tissue surrounds the heart and metabolically active organs. EFT is very metabolically active, releasing atherogenic and inflammatory substrates including TNF-alpha, inhibitor of plasminogen activator, visfatin, leptin, omentin, and angiotensin. ${ }^{22}$ Free fatty acids and adiponectin released by EFT trigger atherosclerosis of the myocardium because of the lack of any barrier between myocardial EFT and coronary vessels. ${ }^{23}$ EFT levels were higher in AS patients than controls.

Metabolic syndrome is described as a group of various abnormal metabolic risk factors such as obesity, dyslipidemia, increased blood pressure, increased plasma glucose levels, prothrombotic condition and proinflammatory state. Metabolic syndrome was found to be more common in
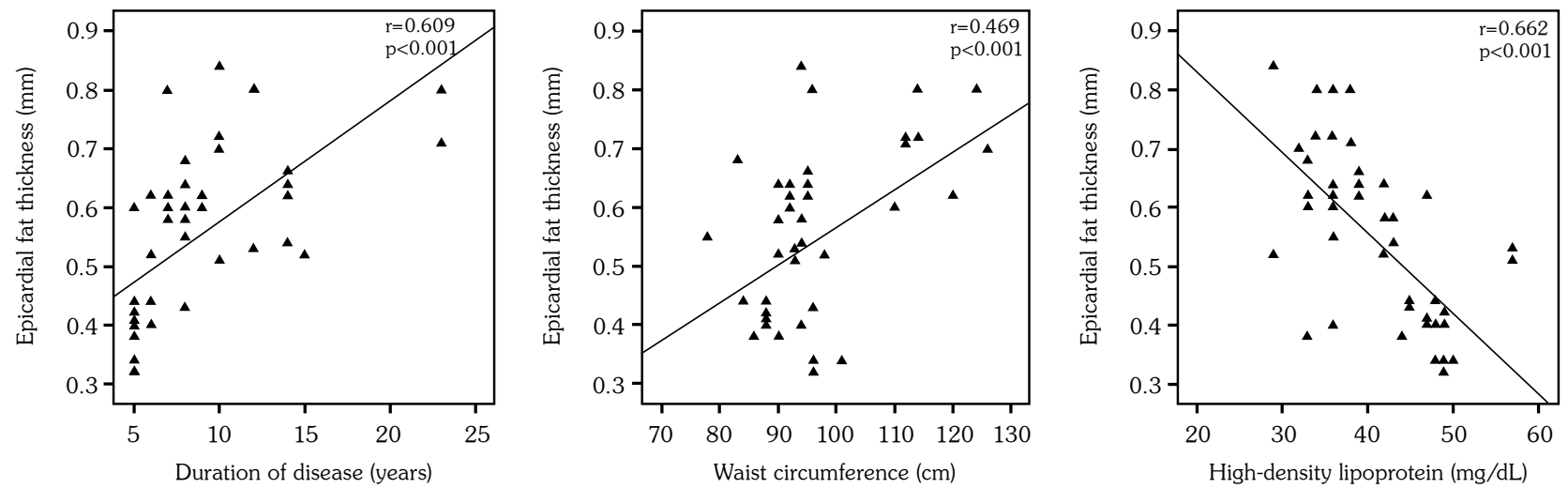

Figure 1. Correlation analyses between epicardial fat thickness and clinical parameters. 
AS patients. ${ }^{24,25}$ Malesci et al. $^{25}$ showed that the prevalence of metabolic syndrome was $46 \%$ in AS patients and $11 \%$ in others. Risk factors for metabolic syndrome, including obesity, hypertension, hyperlipidemia, disturbances in glucose metabolism, and elevated insulinresistance, were higher in AS patients. ${ }^{5}$ EFT surrounds both the ventricles and the coronary artery, and its extent was positively correlated with both BMI and WC, possibly contributing to the development of coronary artery disease. ${ }^{26-28}$ Ormseth et al. ${ }^{29}$ showed that the EFT was associated with risk factors for metabolic syndrome and cardiometabolic conditions in rheumatoid arthritis patients. In the present study, we found that BMI, WC, and TG level were elevated, and HDL level was lower in AS patients compared to controls. In addition, EFT values were correlated with BMI, WC, and disease duration, indicating that cardiometabolic risk factors were elevated in AS patients.

The principal limitation of our study was the small sample size, which afforded only a low statistical power upon equivalence testing. Thus, false-negative results were possible. Other limitations included the cross-sectional design and lack of follow-up. Comprehensive prospective studies featuring long-term follow-up are needed to determine the relationship between EFT levels and cardiovascular outcomes in AS patients. In conclusion, EFT, a cardiometabolic risk factor, was elevated in AS patients, and this may reflect subclinical cardiovascular involvement in these patients.

\section{Declaration of conflicting interests}

The authors declared no conflicts of interest with respect to the authorship and/or publication of this article.

\section{Funding}

The authors received no financial support for the research and/or authorship of this article.

\section{REFERENCES}

1. Genre F, López-Mejías R, Rueda-Gotor J, MirandaFilloy JA, Ubilla B, Carnero-López B, et al. Patients with ankylosing spondylitis and low disease activity because of anti-TNF-alpha therapy have higher TRAIL levels than controls: a potential compensatory effect. Mediators Inflamm 2014;2014:798060.
2. van der Horst-Bruinsma IE, Nurmohamed MT, Landewé RB. Comorbidities in patients with spondyloarthritis. Rheum Dis Clin North Am 2012;38:523-38.

3. Bremander A, Petersson IF, Bergman S, Englund M. Population-based estimates of common comorbidities and cardiovascular disease in ankylosing spondylitis. Arthritis Care Res (Hoboken) 2011;63:550-6.

4. Gonzalez-Juanatey C, Vazquez-Rodriguez TR, Miranda-Filloy JA, Dierssen T, Vaqueiro I, Blanco R, et al. The high prevalence of subclinical atherosclerosis in patients with ankylosing spondylitis without clinically evident cardiovascular disease. Medicine (Baltimore) 2009;88:358-65.

5. MathieuS, MotreffP, SoubrierM.Spondyloarthropathies: an independent cardiovascular risk factor? Joint Bone Spine 2010;77:542-5.

6. Iacobellis G, Corradi D, Sharma AM. Epicardial adipose tissue: anatomic, biomolecular and clinical relationships with the heart. Nat Clin Pract Cardiovasc Med 2005;2:536-43.

7. Iacobellis G, Ribaudo MC, Assael F, Vecci E, Tiberti C, Zappaterreno A, et al. Echocardiographic epicardial adipose tissue is related to anthropometric and clinical parameters of metabolic syndrome: a new indicator of cardiovascular risk. J Clin Endocrinol Metab 2003;88:5163-8.

8. Malavazos AE, Ermetici F, Cereda E, Coman C, Locati M, Morricone L, et al. Epicardial fat thickness: relationship with plasma visfatin and plasminogen activator inhibitor-1 levels in visceral obesity. Nutr Metab Cardiovasc Dis 2008;18:523-30.

9. Kremen J, Dolinkova M, Krajickova J, Blaha J, Anderlova K, Lacinova Z, et al. Increased subcutaneous and epicardial adipose tissue production of proinflammatory cytokines in cardiac surgery patients: possible role in postoperative insulin resistance. J Clin Endocrinol Metab 2006;91:4620-7.

10. Iacobellis G, Bianco AC. Epicardial adipose tissue: emerging physiological, pathophysiological and clinical features. Trends Endocrinol Metab 2011;22:450-7.

11. Iacobellis G, Lonn E, Lamy A, Singh N, Sharma AM. Epicardial fat thickness and coronary artery disease correlate independently of obesity. Int $\mathrm{J}$ Cardiol 2011;146:452-4.

12. Nilgun $U$, Kurt $M$, Atcı N, Yağız E, Güler $H$, Turhanoğlu A. Increased Epicardial Fat Tissue is a Marker of Subclinic Atherosclerosis. Arch Rheumatol 2014;29:1-6.b

13. Resorlu H, Akbal A, Resorlu M, Gokmen F, Ates C, Uysal $\mathrm{F}$, et al. Epicardial adipose tissue thickness in patients with ankylosing spondylitis. Clin Rheumatol 2015;34:295-9.

14. van der Linden S, Valkenburg HA, Cats A. Evaluation of diagnostic criteria for ankylosing spondylitis. A proposal for modification of the New York criteria. Arthritis Rheum 1984;27:361-8.

15. Söker G, Gülek B, Tufan MA, Söker E, Kelle B, Öztürk AB. Early diagnosis of hip joint involvement 
of ankylosing spondylitis using magnetic resonance imaging in the absence of clinical and x-ray findings. Arch Rheumatol 2014;29:99-104.

16. Yildirir A, Aksoyek S, Calguneri M, Aytemir K, Apras S, Kiraz S, et al. No evidence of cardiac autonomic involvement in ankylosing spondylitis, as assessed by heart rate variability. Clin Rheumatol 2001;20:185-8.

17. Brunner F, Kunz A, Weber U, Kissling R. Ankylosing spondylitis and heart abnormalities: do cardiac conduction disorders, valve regurgitation and diastolic dysfunction occur more often in male patients with diagnosed ankylosing spondylitis for over 15 years than in the normal population? Clin Rheumatol 2006;25:24-9.

18. van der Linden S, Valkenburg HA, Cats A. Evaluation of diagnostic criteria for ankylosing spondylitis. A proposal for modification of the New York criteria. Arthritis Rheum 1984;27:361-8.

19. Ben-Zvi I, Goldenberg I, Matetzky S, Grossman C, Elis A, Gavrielov-Yusim N, et al. The impact of inflammatory rheumatic diseases on the presentation, severity, and outcome of acute coronary syndrome. Clin Rheumatol 2014. [Epub ahead of print].

20. Iacobellis G, Assael F, Ribaudo MC, Zappaterreno A, Alessi G, Di Mario U, et al. Epicardial fat from echocardiography: a new method for visceral adipose tissue prediction. Obes Res 2003;11:304-10.

21. Iacobellis G, Willens HJ, Barbaro G, Sharma AM. Threshold values of high-risk echocardiographic epicardial fat thickness.Obesity (Silver Spring) 2008; 16:887-92.

22. Iacobellis G, Barbaro G. The double role of epicardial adipose tissue as pro- and anti-inflammatory organ.
Horm Metab Res 2008;40:442-5.

23. Sacks HS, Fain JN. Human epicardial adipose tissue: a review. Am Heart J 2007;153:907-17.

24. Sidiropoulos PI, Karvounaris SA, Boumpas DT. Metabolic syndrome in rheumatic diseases: epidemiology, pathophysiology, and clinical implications. Arthritis Res Ther 2008;10:207.

25. Malesci D, Niglio A, Mennillo GA, Buono R, Valentini G, La Montagna G. High prevalence of metabolic syndrome in patients with ankylosing spondylitis. Clin Rheumatol 2007;26:710-4.

26. Flüchter S, Haghi D, Dinter D, Heberlein W, Kühl HP, Neff W, et al. Volumetric assessment of epicardial adipose tissue with cardiovascular magnetic resonance imaging. Obesity (Silver Spring) 2007;15:870-8.

27. Wang TD, Lee WJ, Shih FY, Huang CH, Chang YC, Chen WJ, et al. Relations of epicardial adipose tissue measured by multidetector computed tomography to components of the metabolic syndrome are regionspecific and independent of anthropometric indexes and intraabdominal visceral fat. $\mathrm{J}$ Clin Endocrinol Metab 2009;94:662-9.

28. Silaghi A, Piercecchi-Marti MD, Grino M, Leonetti G, Alessi MC, Clement K, et al. Epicardial adipose tissue extent: relationship with age, body fat distribution, and coronaropathy. Obesity (Silver Spring) 2008;16:2424-30.

29. Ormseth MJ, Lipson A, Alexopoulos N, Hartlage GR, Oeser AM, Bian A, et al. Association of epicardial adipose tissue with cardiometabolic risk and metabolic syndrome in patients with rheumatoid arthritis. Arthritis Care Res (Hoboken) 2013;65:1410-5. 